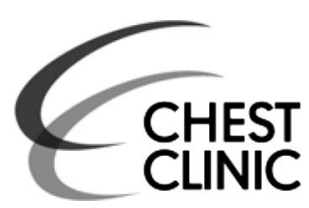

CASE BASED DISCUSSIONS

\title{
Treatment failure due to use of a 'ramp' option on pressure support home ventilators
}

\author{
Jesus Gonzalez-Bermejo, ${ }^{1,2}$ Claudio Rabec, ${ }^{3}$ Christophe Perrin, ${ }^{4}$ Bruno Langevin, ${ }^{5}$ \\ Jean Louis Pepin, ${ }^{6}$ Daniel Rodenstein, ${ }^{7}$ Jean Paul Janssens, ${ }^{8}$ on behalf of the \\ SomnoNIV group
}

${ }^{1}$ UMRS1158 Neurophysiologie respiratoire expérimentale et clinique, Sorbonne Universités, UPMC Univ Paris 06, INSERM, Paris, France

${ }^{2}$ Assistance publique-Hôpitaux de Paris, Groupe Hospitalier Pitié-Salpêtrière, Service de Pneumologie et Réanimation Médicale, Paris, France ${ }^{3}$ Service de Pneumologie et Réanimation Respiratoire, Centre Hospitalier et Universitaire de Dijon, Dijon, France

${ }^{4}$ Service de Pneumologie, Centre Hospitalier de Cannes, Cannes, France

${ }^{5}$ Service de réanimation, Centre Hospitalier, Ales, France

${ }^{6}$ Département de Pneumologie et Laboratoire du sommeil, CHRU, Grenoble, France ${ }^{7}$ Service de Pneumologie, Cliniques Universitaires Saint Luc, Université Catholique de Louvain, Bruxelles, Belgium

${ }^{8}$ Pulmonary Division, Geneva University Hospitals, Geneva, Switzerland

\section{Correspondence to} Dr Jesus Gonzalez-Bermejo, Department of Pneumology and Intensive Care Medicine, Groupe Hospitalier Pitié Salpêtrière, 47-83 boulevard de l'Hôpital, Paris 75651, Cedex 13, France; jesus. gonzalez@aphp.fr

Received 25 January 2016 Revised 6 March 2016 Accepted 7 March 2016 Published Online First 7 April 2016

\section{INTRODUCTION}

Algorithms for monitoring home non-invasive ventilation (NIV) have been recently proposed. ${ }^{1-3}$ Following this strategy, we detected three cases of transient ineffective ventilation due to the use of a 'ramp' option on home pressure support (PS) ventilators. The 'ramp' option is a comfort setting initially made available on CPAP devices. This option exists in pressure-cycled ventilators, allowing a progressive increase of expiratory positive airway pressure (EPAP) only. A " ramp » option has also recently been made available for PS: to our knowledge, three home ventilators (Stellar, Resmed, Australia; Prisma, Weinmann, Germany; Dreamstar Duo, Sefam, France) now provide this feature, allowing a stepwise increase of PS from $2 \mathrm{~cm} \mathrm{H}_{2} \mathrm{O}$ to the target PS within 5-45 min.

\section{CASE REPORTS}

Patients whose data are entered in this work all signed a consent form authorising use of these data for research and teaching purposes.

Three patients previously treated for obstructive sleep apnoea (OSA) with CPAP devices, were switched to NIV because of uncontrolled hypoventilation due to obesity hypoventilation syndrome (OHS) $(n=2)$ or diaphragmatic dysfunction $(n=1)$ (table 1). NIV was introduced using a single circuit pressure-targeted ventilator (Stellar 100, Resmed, Australia) and a calibrated leak, in a 'Spontaneous/ Timed mode' (assisted PS with a backup respiratory rate). Patients were monitored using a polygraph coupled to the ventilator (Reslink, Resmed, Australia) $)^{2}$ (table 1).

The three patients, who had previously used a 'ramp' option on their CPAP device, requested from their home care provider a similar setting on their home ventilator.

During ramp time, all three patients presented with dyspnoea and discomfort when launching NIV, probably due to insufficient PS, inducing deep desaturations in patient 1 and increase in respiratory rate and unrewarded inspiratory efforts in patients 2 and 3. Patients 1 and 2 removed transiently their device during the night, causing a recurrence of the reported respiratory abnormalities. Both patients were adequately ventilated when they reached the expected EPAP and PS settings (part B of the figure 1).

Patient 3 tolerated neither the ramp option on both EPAP and PS, nor the immediate exposure to high levels of PS $\left(20 \mathrm{~cm} \mathrm{H}_{2} \mathrm{O}\right)$. However, she tolerated perfectly well the same PS with a ramp only on EPAP (VPAP S9, Resmed, Australia)

\section{DISCUSSION}

This report shows that implementation of a 'ramp' on PS home ventilators may be a cause of transient ineffective ventilation and desaturation and/or patient discomfort.

For CPAP devices, the 'ramp' function is considered as a comfort setting and can be adjusted by the patient himself. Although use of a 'ramp' has been reported as a cause of treatment failure in OSA,${ }^{4}$ clinicians usually tend to consider that a 'ramp' on CPAP is not dangerous and probably improves comfort.

The problem is not the same with PS. Only three ventilators, to our knowledge, have a 'ramp' function on PS. On these ventilators, the progressive increase in pressure applies to PS and PEP simultaneously.

There is a hypothetical indication for a 'ramp' option on PS devices for patients who do not tolerate immediate exposure to the preset level of PS when they put on their ventilator, and feel more comfortable with a progressive increase in PS. The pros and cons of this option would be difficult to determine in a clinical trial, because of the wide range of possible settings (duration and pressure span of ramp) and the subjective nature of the main end point (patient comfort). The three cases reported show that use of a ramp on PS may compromise the efficacy of NIV, especially in patients with orthopnoea requiring full PS immediately when reclining (as in case number 3). This option may be especially questionable in subjects who have multiple awakings during the night and thus could use this option repeatedly: patients would appear compliant but time under NIV would include multiple subtherapeutic episodes. Additionally, in patients with orthopnoea, that is, subjects with diaphragmatic dysfunction, this option may increase discomfort and delay relief from dyspnoea. Furthermore, in OHS, which is most often associated with OSAS, a prolonged 'ramp time' can delay appropriate pneumatic upper airway stenting and thus explain residual obstructive apnoeas during the ramp phase.

In summary, using a PS ramp option during NIV (1) can compromise NIV efficacy and may be poorly tolerated; (2) should not be an option that 
Table 1 Characteristics of the patients and ventilator settings in cases reported

\begin{tabular}{|c|c|c|c|c|c|c|c|c|c|}
\hline Case & Diagnosis & BMI $\left(\mathrm{kg} / \mathrm{m}^{2}\right)$ & VC (\%) & Baseline AHI & $\begin{array}{l}\text { Baseline } \mathrm{PaCO}_{2} / \mathrm{PaO}_{2} \\
(\mathrm{~mm} \mathrm{Hg})\end{array}$ & $\begin{array}{l}\text { IPAP/EPAP } \\
\left(\mathrm{cm} \mathrm{H} \mathrm{H}_{2} \mathrm{O}\right)\end{array}$ & $\begin{array}{l}\text { Rise time } \\
\text { (ms) }\end{array}$ & $\mathrm{Ti}_{\text {MIN/ }} \mathrm{Ti}_{\text {MAX }}(\mathrm{ms})$ & $\begin{array}{l}\text { Backup } \\
\text { RR (/mn) }\end{array}$ \\
\hline 1 & $\mathrm{OHS}$ & 57 & 69 & 117 & $57 / 61$ & $22 / 14$ & 400 & $0.8 / 1.8$ & 12 \\
\hline 2 & $\mathrm{OHS}$ & 35 & 83 & 35 & $53 / 71$ & $27 / 15$ & 200 & $0,8 / 1.8$ & 14 \\
\hline 3 & NMD & 37 & 54 & 22 & $48 / 82$ & $18 / 8$ & 200 & $0.8 / 1.8$ & 14 \\
\hline
\end{tabular}

Figure 1 All recordings were obtained from a monitoring device coupled to the ventilator (Reslink, Resmed, Sydney, Australia). A: Recurrent desaturations (case 1) or increased respiratory rate (RR) (case 2 and 3 ), and low flow during ramp period. B: Tracing during pressure support with target settings. $\mathrm{SpO}_{2}$, pulse oxymetry.
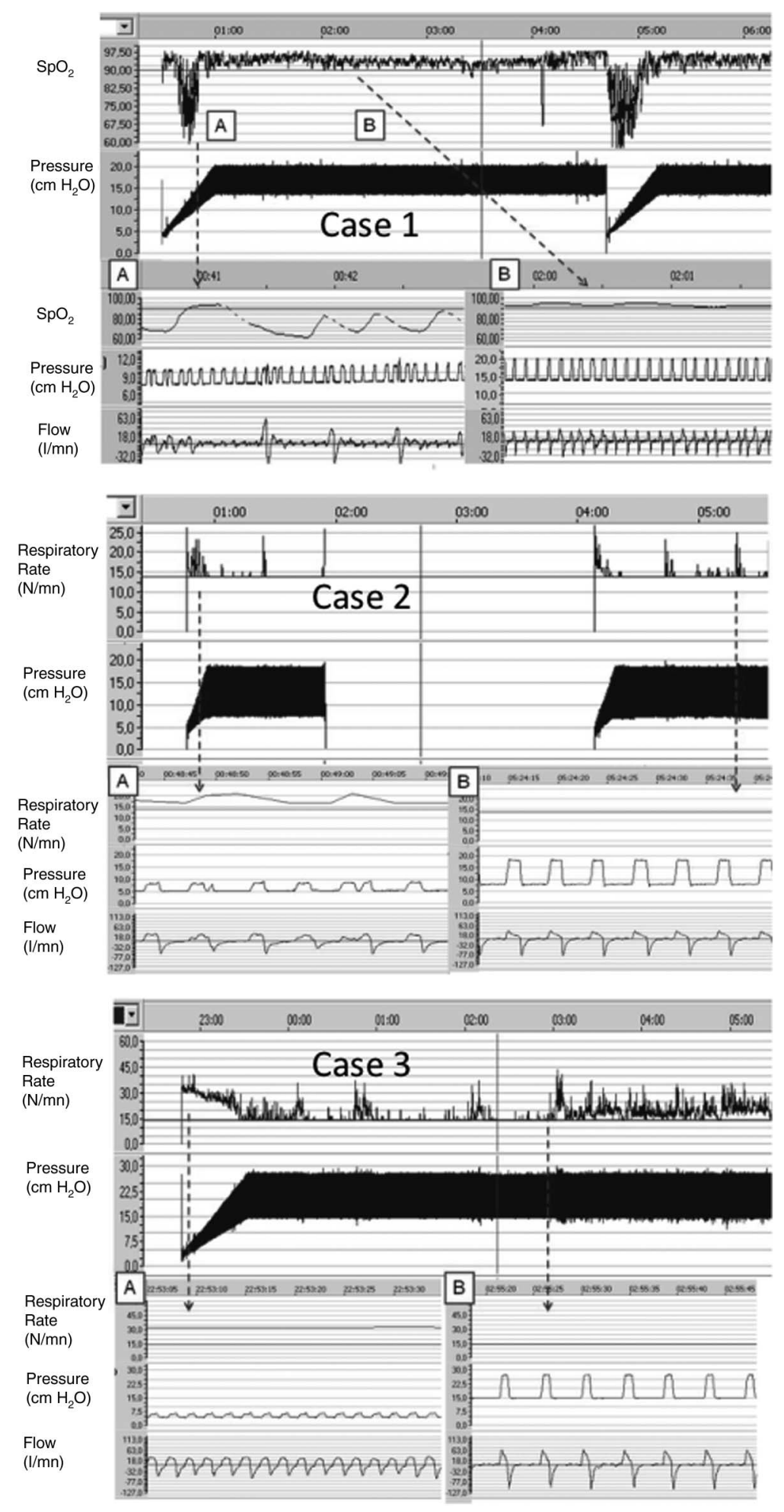


\section{Chest clinic}

the patient can activate by himself as in CPAP devices; (3) should be set only by an experienced clinician aware of potential drawbacks; (4) its activation should appear explicitly on the screen of the device. If, in spite of the previously discussed drawbacks, a PS 'ramp' option is selected, initial PS level should be at least 5$6 \mathrm{~cm} \mathrm{H}_{2} \mathrm{O}$, and time to attain the preset PS should be as short as possible. All settings, including ramp function, should be not altered without detailed clinical assessment and consultation. Use of the ramp function should be to improve comfort and aid compliance and should be reviewed along with the rest of the ventilator prescription at each clinic assessment with the aim of always using the minimum time and pressure gap required to enhance sleep onset and NIV adherence.

Contributors JG-B: (1) Substantial contributions to the conception or design of the work, or the acquisition, analysis or interpretation of data. (2) Drafting the work or revising it critically for important intellectual content. (3) Final approval of the version published. (4) Contributor as being responsible for the overall content as guarantor(s). CR, CP, BL, JLP, DR and JPJ: (1) Substantial contributions to the conception or design of the work, or the acquisition, analysis or interpretation of data. (2) Drafting the work or revising it critically for important intellectual content. (3) Final approval of the version published.
Funding Investissement d'avenir ANR (10-AlHU 6).

Competing interests None declared.

\section{Patient consent Obtained.}

Ethics approval Institutional Review Board of the French learned society for respiratory medicine- Société de Pneumologie de Langue Française.

Provenance and peer review Not commissioned; externally peer reviewed.

\section{REFERENCES}

1 Gonzalez-Bermejo J, Perrin C, Janssens JP, et al. Proposal for a systematic analysis of polygraphy or polysomnography for identifying and scoring abnormal events occurring during non-invasive ventilation. Thorax 2012;67:546-52.

2 Janssens JP, Borel JC, Pépin JL. Nocturnal monitoring of home non-invasive ventilation: the contribution of simple tools such as pulse oximetry, capnography, built-in ventilator software and autonomic markers of sleep fragmentation. Thorax 2011;66:438-45.

3 Rabec C, Rodenstein D, Leger $\mathrm{P}$, et al. Ventilator modes and settings during non-invasive ventilation: effects on respiratory events and implications for their identification. Thorax 2011;66:170-8.

4 Pressman MR, Peterson DD, Meyer TJ, et al. Ramp abuse. A novel form of patient noncompliance to administration of nasal continuous positive airway pressure for treatment of obstructive sleep apnea. Am J Respir Crit Care Med 1995;151:1632-4. 